\title{
Assemblers and Fabricators
}

National Cancer Institute

\section{Source}

National Cancer Institute. Assemblers and Fabricators. NCI Thesaurus. Code C122429.

Workers who use tools, machines, and their hands to assemble finished products and the parts that go into them. 